\title{
Analysis of the Validity of Environmental Kuznets Curve for the Baltic States
}

\author{
Giedrè Lapinskienè ${ }^{1}$, Manuela Tvaronavičiene் ${ }^{2}$, Pranas Vaitkus ${ }^{3},{ }^{1-3}$ Vilnius Gediminas Technical University
}

\begin{abstract}
The paper analyses a traditional Environmental Kuznets Curve (EKC) relationship between greenhouse gases (GHG) and gross domestic product (GDP), extending the research to include some additional factors, such as environmental tax, research and development expenditure, implicit tax rate on energy, primary production of coal and lignite, energy intensity of the economy taken from the Eurostat database. The EKC indicates that, at the early stages of economic growth, pollution increases with the growing use of resources, but when a certain level of income per capita is reached, the trend reverses so that, at a higher development stage, further economic growth leads to the improvement of the environment. In the first part of the research, the validity of the reduced EKC for the Baltic region for the period $1995-2008$ is determined. In the second part, the impact of selected factors is statistically tested. In both cases, the standard cubic equation is used because it is believed that this model is the most accurate for the development stage of this region. The research results may be useful for climate change policy design.
\end{abstract}

Keywords - greenhouse gases, Environmental Kuznets Curve, Baltic States, climate change.

\section{INTRODUCTION}

The most relevant environmental problem today is associated with the development of strategies, which could help to control climate change $[24,10]$. At the highest political level, environmental problems have been viewed as very important for the development of the country since 1972, when the Stockholm Conference on the Human Environment was held. The new concept of sustainable development as the major developing strategy, equally embracing economic, social and environmental pillars, was introduced. The term 'sustainability' was derived from forestry where this term was related to natural development of forests and was called 'Sustained Yield Forestry' [29]. At the World Summit in Rio de Janeiro in 1992, the concept of sustainable development as the major developing strategy equally embracing economic, social and environmental pillars has been recognized as a fundamental ideology. Over a period of forty years much effort was made to accept and implement the new paradigm at national levels. For example, the Lithuanian National Strategy for Sustainable Development was approved by the Government of the Republic of Lithuania in 2003. Despite this fact, the rapid degradation of environmental resources and increasing pollution led to the recognition of some environmental problems as priority tasks. The UNFCCC Kyoto Protocol is the agreement among countries obliging them to strictly manage, control and reduce levels of greenhouse gases. It was not sufficient to include greenhouse gas indicators in the set of sustainable development variables. The main problem of how to maintain the growth rate stable and at the same time slow down the level of GHG is also described in the European strategy 2020. Hence, researches have been working in this direction in order to find new solutions to the problem of environmental management.

Some of these studies rely on the Environment Kuznets Curve approach. The EKC shows the relationship between various indicators of environmental degradation (air pollutants, e.g. $\mathrm{CO} 2, \mathrm{SO} 2, \mathrm{GHG}$, water pollutants, waste and other specific environmental pollutants) and economic development generally expressed as income per capita or GDP. Originally the environmental curve was derived from the Kuznets curve. In 1955, researchers considered the relationship between income inequality and income per capita at different stages of economic development [23]. This relationship became known as the Kuznets curve. In the 90s, environmental economists had built on this concept by hypothesizing the same type of relationship between the level of environmental degradation and income growth [17, 18, 30]. Reference [31] explained that at the early stages of economic growth, degradation and pollution increased, but after reaching a certain level of income per capita, the trend reversed and the economic growth lead to environmental improvement [31]. Such a path of the relationship between environmental indicators and economic growth has been called the inverted U-shaped function of income per capita

The presented investigation has two aims:

1. The first aim is to analyse the influence of GDP on GHG in order to test the EKC hypothesis.

2. The second aim is to analyse some additional factors, which might impact the relationship between GHG and GDP.

The data for the full sample chosen is the time series of the period from 1995-2008 in the Baltic countries as a region representing similar development levels, geographic areas and having some similar EKC patterns [26]. The analysis of the specific factors, influencing the path of the $\mathrm{EKC}$, may be important for developing and pursuing environmental or sustainable development policies.

The specific objectives of this paper are:

- to review and asses the available literature on $\mathrm{EKC}$;

- to choose relevant factors for the model based on theoretical studies and economic logic;

- to test the raised hypothesis statistically.

The paper has the following structure. Section 2 addresses some important theoretical issues based on the concepts considered. Sections 3 and 4 provide a comparative analysis 
and describe the main findings of the research. The last section summarizes the results, providing the concluding remarks and defining possible areas of further research.

\section{LITERATURE REVIEW AND RAISING THE HYPOTHESES}

Studies on air pollution indicators were carried out by researchers and the inverted U relationship between GDP and some air indicators was found [17, 18, 30]. Many journals, such as Ecological Economics, Energy Policy, Energy Economics, Economic Modelling, and others, published the articles considering this problem. Researches used environment-related databases, such as World Bank, OECD, Eurostat and national statistics. States and international organizations invest in data collection and storage in reliable databases, because the quality of data helps to understand more clearly the reasons for environmental degradation. Researches used different environmental quality indicators air pollutants, e.g. $\mathrm{CO}_{2}, \mathrm{SO}_{2}$, and $\mathrm{GHE}$, water indicators, waste and other specific environmental indicators. Time series techniques were used for a single region or location [28, 14, 9]. Panel data techniques were used for the analysis of several regions $[19,7]$.

The relationship between carbon dioxide variable and economic growth was first analysed in a World Bank study. The World Bank analysis of cross-country data from 1980 to 1990 revealed that the additional carbon dioxide (as the main gas of GHG) released into the atmosphere due to human activities between 1980 and 1989 came principally from fossil fuels. The researchers emphasized, that future trends in GHG concentrations would depend on a number of criteria and economic growth would be one of them. The results of the research showed an increasing trend in the relationship between carbon dioxide and GDP [33]. Reference [21] continued the studies of $\mathrm{CO}_{2}$, because this indicator greenhouse gas which is central to the global warming prediction, was found that its emissions did not show the same EKC pattern. Instead, $\mathrm{CO}_{2}$ emissions monotonically increased with income [21]. Reference [6] considered that EKCs exist only for local air pollutants. He suggested that indicators with a more global impact either increase monotonically with income or else have predicted turning points at high per capita income [6]. Reference [3] explained that GHG is a special pollutant, contributing to global warming, which had international and intergenerational dimensions. They argued that the inverted U-shaped relationship did not hold for GHG and economic growth [3]. Reference [15] tested various functional forms of carbon dioxide and GDP relationship for the group of OECD and non-OECD countries. He found that, while there is evidence of an inverted- $U$ pattern for the group of OECD countries, this does not hold true for non-OECD countries [15]. Some critical researchers think that the model is overly simplistic or generally inadequate and the alternative approaches might be much more fruitful [32]. In this work, we continue the search for new applications of the EKC model. The main research question: Can the EKC form be supported by the analysis of the impact of GDP growth on the GHG in the Baltic region in the period of 1995-2008?

According to reference [30], the development trajectory for pollution is likely to reflect both market forces and changes in government regulation. As a result, it is reasonable to expect that economies would pass through "stages of development," in which at least some aspects of the environmental quality first deteriorate and then improve [30]. Following this economic logic, many researchers used various additional factors and proved that they can have some additional positive or negative impact on the relationship between pollution and GDP. The latest studies grouped the factors or causes of pollution into economical, demographic and governance areas $[5,16,25]$.

The main economic indicator which captures human activities is GDP. The main sources of pollution are associated with the sectors of energy, transport, industry, agriculture, and waste disposal, while afforestation has a positive effect on the greenhouse gas level [16]. Hence, the economic structure and, specifically, industrialization are very important factors, which might negatively affect GHG. Researchers used various indicators referring to the economic structure -the capitalabundance ratio $(\mathrm{K} / \mathrm{L})[20]$, the percent of the total output of goods and services provided by the industrial sector [4] and industry value added as percentage of GDP [1]. The energy sector is defined as the most robust determinant of GHG emission. Researchers used various indicators to evaluate the importance of the energy sector's particularities - the high share of electricity production from coal and oil sources in the total electricity production [25] and the gas price as the additional variable, which had partially explained the results [14].

Demographic factors are defined as socio-economic characteristics of a population expressed statistically. Population density is the indicator which logically leads to increasing pollution [30]. The level of urbanization is often used as the most common factor, because it leads to a rise in energy users and transportation [5]. Education level and income inequality are also factors that positively affect environmental quality.

Governance factors cover the governance and the quality of institutions. Researches used such variables like political rights and civil liberties [27], corruption level and other variables measuring whether or not the party of the chief executive has a left-wing orientation, a dictatorship dummy or a second measure of democracy [16].

In order to assess the influence of other factors, some new components were introduced into the model. The novelty of this article is that a set of additional variables related to environmental policy instruments are tested for their impact on the relationship between GHG and GDP.

Hypothesis 2 Do such additional factors as economic structure, environmental tax, research and development expenditure, implicit tax rate on energy, primary production of coal and lignite and energy intensity of the economy influence the level of GHG, and, if so, do they produce a positive or negative effect (Table I)? 
TABLE I

ADDITIONAL FACTORS

\begin{tabular}{|c|c|c|c|}
\hline Indicator & Description & Expected sign & Remarks \\
\hline Sect_structure & $\begin{array}{l}\text { Agriculture }+ \text { Industry }+ \text { Construction value added as } \\
\text { percentage of total }\end{array}$ & Positive & After the first calculation - statistically insignificant \\
\hline TAX2 & Percent of the total taxes and social contributions & Negative & Statistically significant (results is presented in the Table II) \\
\hline ENERGTAX & $\begin{array}{l}\text { Ratio between energy tax revenues and final energy } \\
\text { consumption ((Euro per tonne) }\end{array}$ & Negative & Statistically significant (results is presented in the Table II) \\
\hline $\mathrm{RD}$ & $\begin{array}{l}\text { Research and experimental development } \\
\text { expenditure (EUR). }\end{array}$ & Negative & Statistically significant (results is presented in the Table II) \\
\hline SOLID & Primary production of coal and lignite (tonnes). & Positive & Statistically significant (results is presented in the Table II) \\
\hline ENINTENSITY & $\begin{array}{l}\text { Ratio between the gross inland consumption of } \\
\text { energy and the GDP (kg /EUR) }\end{array}$ & Positive & Statistically significant (results is presented in the Table II) \\
\hline
\end{tabular}

\section{DATA AND METHODOLOGY OF ANALYSIS}

In the present analysis, three considered countries present the development stage from efficiency-driven to innovationdriven economy [34]. The data for the full sample chosen is available in the Eurostat database for the period of 1995-2008. The pooled EGLS (cross-section weights) regression method was chosen to link the time-series cross sectional data of different countries. Eviews was selected as the instrument of analysis. In this research, GHG represents a dependable variable of the environmental characteristics. This variable was identified and described in the United Nations Framework Convention on Climate Change (UNFCCC), the Kyoto Protocol and the Decision 280/2004/EC and presented in the Eurostat database [12]. The main elements of the emitted greenhouse gases were defined in the Kyoto basket protocol as follows: carbon dioxide, methane, nitrous oxide, hydrofluorocarbons, perfluorocarbons and sulphur hexafluoride [24]. Carbon dioxide is mainly produced by burning fossil fuels, in particular, for electricity generation and operation of transport and industry. Changes in the level of $\mathrm{CO}_{2}$ are also caused by deforestation and declining algae in the water. Generation of methane is associated with human activities, such as gas mining and burning, animal husbandry, rice cultivation and dumps. Nitrous oxide is obtained in producing various nitrogen fertilizers, fuel burning and chemical industry. F-gases (hydrofluorocarbons, perfluorocarbons and sulphur hexafluoride) are gases generated only by human activities, because there are no natural sources of these gases in the environment. The amount of greenhouse gases in every country is estimated by combining information on human activity with a coefficient quantifying the emissions from that activity. Such coefficients are termed 'emission factors', and may be used as follows:

\section{Emissions $=$ activity data $*$ emissions factor $[11]$}

GDP expressed in purchasing power-parity is specifically used in this research in order to minimise the potential differences in prices of the countries, which may be at different stages of development. Usually, various GDP expressions are taken by researchers as the main independent variables $[17,18,30]$.
According to reference [11], the variable of environmental taxes is described as a tax, the tax base of which is a physical unit of something that has a proven, specific negative impact on the environment. In this research, it is taken as a percent of the total taxes and social contributions [11].

According to reference [11], an implicit tax rate on energy (Euro per tonne) is defined as the ratio between energy tax revenues (Euro) and final energy consumption calculated for a calendar year (tonnes of oil equivalent) [11].

According reference [12], research and experimental development include all expenditures within the enterprise business sector on the national territory during a given period. Research and experimental development expenditure is shown as a percentage of GDP [12].

Reference [12] notes, primary production of coal and lignite comprises of quantities of fuels extracted or produced, which are calculated after performing any operation for removal of inert matter [12].

In accordance with reference [12], energy intensity of the economy ( $\mathrm{kg} / \mathrm{EUR})$ is the ratio between the gross inland consumption of energy and the GDP for a given calendar year. It measures the energy consumption of an economy and its overall energy efficiency [12].

To test the first hypothesis, the reduced form approach of the EKC, was used to evaluate the relationship between GHG and GDP and the selected variables. Commonly, three types of regression models - log-linear, quadratic and cubic forms are used in the analysis of the EKC hypothesis [8]. The authors of this work used the cubic form model because it was originally used by Reference [18] and might show the most preferable path of the relationship between GHG and GDP [18]. The data on GHG and GDP was normalised to vary between 0 and 1 of the whole EU sample, the formula is given below.

$$
\left(G D P_{i t}-\min G D P_{E U}\right) /\left(\max G D P_{E U}-\min G D P_{E U}\right)
$$

The selected models are given below.

$$
G H G_{i}=\beta_{0 i}+\beta_{1} G D P_{i}+\beta_{2} G D P_{i}^{2}+\beta_{3} G D P_{i}^{3}+\varepsilon_{i}
$$


Where:

$\mathrm{GHG}_{\mathrm{i}^{-}}$a dependent variable;

$\mathrm{GDP}_{\mathrm{i}}-$ GDP per capita (in PPS) is an independent variable for country $i$;

$\beta$ - the regression coefficient;

$\varepsilon$ - the estimation error coefficient

$G H G_{i}=\beta_{0 i}+\beta_{1} G D P_{1}+\beta_{2} G D P_{1}^{2}+\beta_{3} G D P_{1}^{3}+\beta_{4} R D_{i}+\beta_{5} T A X_{i}+$

$+\beta_{6}$ ENERTAX $+\beta_{7}$ SOLID $+\beta_{8}$ ENERINTENGTY $_{i}+\varepsilon_{i}$

Where:

$\mathrm{RD}_{\mathrm{i}}-$ Research and development, an independent variable for country i;

$\mathrm{TAX}_{\mathrm{i}}$ - Environmental tax, an independent variable for country $\mathrm{i}$;

ENERTAX $_{i}$ - Implicit tax rate on energy, an independent variable for country i;

$\operatorname{SOLID}_{\mathrm{i}}$ - Primary production of coal and lignite, an independent variable for country $i$;

ENERINTENSITY $_{\mathrm{i}}$ - Energy intensity of the economy, an independent variable for country $i$;

The model was validated by considering the adjusted $\mathrm{R}^{2}$ and $\mathrm{p}$-value as the values, indicating the fitness of the regression. The higher the $\mathrm{R}^{2}$ value, the better the explanatory power for the curve fitting. Specifically, the p-value was used to examine the effect of the independent variables on the dependent variable. When the p-value is lower than 0.05 , it indicates that this coefficient has a statistically significant explanatory power with the probability of $95 \%$.

\section{RESULTS OBTAINED IN THE RESEARCH}

In order to validate the hypothesis, the models were tested, using the Eviews software [13]. Two models were calculated based on the data pertaining to it. Data for the years 1995 to 2008 were estimated, using pooled data series with crosssection weighting. The results of the econometric analysis may be discussed from the perspectives of statistical significance of the relationship between per capita factors and per capita GHG emissions. The statistical results of the first model are presented in Table II. It can be seen that, in general, the research confirmed the presence of the inverse U-shaped relationship, indicating that, at a particular level of GDP, the pollution increases with economic growth, but after reaching some threshold, the trend reverses so that, at a higher development stage, further economic growth leads to the improvement of the environment. The path of EKC may be inferred from the signs of the coefficients $\left(\mathrm{NNGDP}^{\wedge} 2\right)>0$ and $\left(\mathrm{NNGDP}^{\wedge} 3\right)<0$. The results found in the charts of every country are presented in Figure 1. It can be seen that it is the beginning of EKC inverted-U. The analysis of signs and sizes of coefficients shows that the turning point is around 0,25 normalized GDP/per capita. Hence, it may be considered that after reaching this point, the trend reverses and the higher level of economic growth results in the environment improvement.
In the second model, some additional variables (economic structure, environmental tax, research and development expenditure, implicit tax rate on energy, primary production of coal and lignite and energy intensity of the economy influence) were tested. The results are given bellow in Table II.

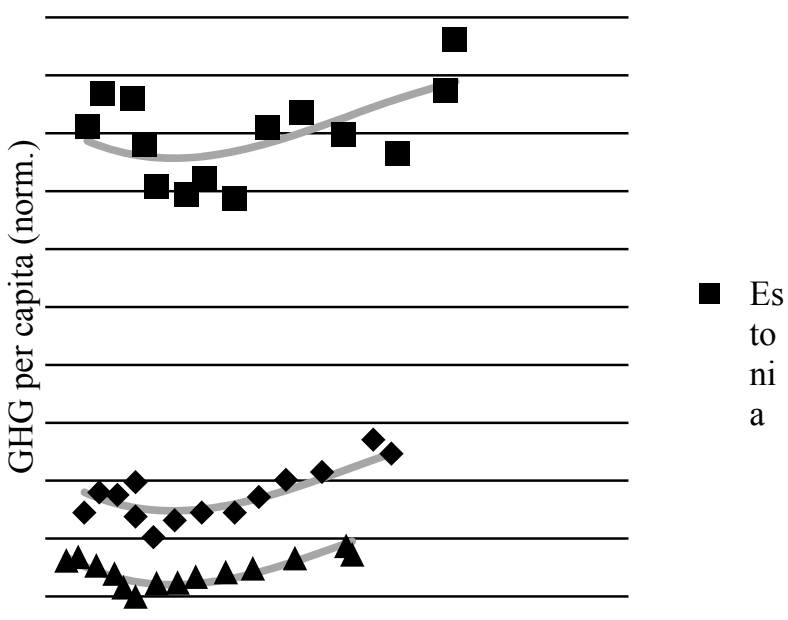

GDP per capita in PPS (norm.)

Fig. 1 Results yielded by the reduced model for the Baltic States in the period 1995-2008

TABLE II

Estimation Results For MODELS For THE PERIOD 1995-2008

\begin{tabular}{|c|c|c|c|c|}
\hline \multirow{2}{*}{} & \multicolumn{2}{|c|}{ First model } & \multicolumn{2}{c|}{$\begin{array}{c}\text { Second model (including } \\
\text { additional factors) }\end{array}$} \\
\cline { 2 - 5 } & Coefficient & Prob. & Coefficient & Prob. \\
\hline Constant & 0.189600 & 0.0000 & -0.072817 & 0.0712 \\
\hline NNGDP & -1.181548 & 0.0019 & 1.990287 & 0.0019 \\
\hline NNGDP^2 & 11.35387 & 0.0103 & -13.97978 & 0.0143 \\
\hline NNGDP^3 & -24.00567 & 0.1068 & 43.76093 & 0.0052 \\
\hline ENERGTAX & - & - & 0.001282 & 0.0013 \\
\hline RD & - & - & -0.000740 & 0.0376 \\
\hline TAX & - & - & -0.012314 & 0.0001 \\
\hline SOLID & - & - & 0.021225 & 0.0000 \\
\hline ENINTENSITY & - & - & 0.000231 & 0.0000 \\
\hline $\begin{array}{c}\text { Fixed Effects } \\
\text { (Cross) }\end{array}$ & & & & \\
\hline $\begin{array}{c}\text { LITHUANIA- } \\
\text { Constant }\end{array}$ & -0.080266 & & -0.013348 & \\
\hline $\begin{array}{c}\text { LATVIA- } \\
\text { Constant }\end{array}$ & -0.144020 & & -0.045579 & \\
\hline $\begin{array}{c}\text { ESTONIA- } \\
\text { Constant }\end{array}$ & 0.224287 & & 0.058927 & \\
\hline $\begin{array}{c}\text { Adjusted R- } \\
\text { squared }\end{array}$ & 0.983236 & & 0.996063 & \\
\hline N & 42 & & 42 & \\
\hline F-statistic & 481.9478 & & 1038.291 & \\
\hline Prob(F-statistic) & 0.000000 & & 0.000000 & \\
\hline $\begin{array}{c}\text { Durbin-Watson } \\
\text { stat }\end{array}$ & 1.374031 & & 1.732623 & \\
\hline & & & & \\
\hline
\end{tabular}


It can be seen in Table II that the considered indicators produce a statistically significant effect. The Implicit tax rate on energy, primary production of coal, as well aslignite and energy intensity of the economy, have a positive mathematical effect whereby GHG increases with the increase in these variables. Research and development, as well as environmental tax demonstrate a negative mathematical effect on GHG. Four of these indicators are variables which are directly related with the energy sector (the processes taking place in this sector strongly influence climate change). The effective measure used in the environmental policy is associated with environmental taxes. The results obtained show that their growth helps to reduce the level of GHG. However, the ratio of energy tax revenues does not have the expected impact. One of the reasons might be that it is estimated implicitly, therefore this requires further investigation. Energy intensity of the economy obtained expected sign because it shows the efficiency of energy use. The quantity of primary production of coal and lignite directly affects the level of GHG, and this is easy to explain. In the considered model, this was primarily and specifically related to Estonia which produces a part of energy from coal. Research and development is the only factor which is not directly related with the energy sector. The use of innovation in all branches of the economy produces an indirect positive effect on the level of GHG

\section{V.CONCLUSION}

The paper considers the traditional EKC relationship between greenhouse gases and gross domestic product, extending the research to include some additional factors, such as environmental tax, research and development expenditure, implicit tax rate on energy, primary production of coal and lignite and energy intensity of the economy taken from the Eurostat database. The data for the full sample chosen is the time series of the period 1995-2008 in the Baltic countries. The research confirmed the presence of the inverse U-shaped relationship, indicating that, at a particular level of GDP and economic growth, the pollution increases, but after reaching some threshold, the trend reverses so that, at a higher development stage, further economic growth leads to the improvement of the environment. All additional indicators are important factors in managing the process of climate change. Four of these indicators are variables that are directly related to the energy sector. The results yield by the second model show that the selected indicators have a statistically significant effect. The implicit tax rate on energy, primary production of coal and lignite and energy intensity of the economy produce a positive mathematical effect on GHG - their increase leads to raise the GHG level. Research and development, as well as environmental tax demonstrate a mathematical negative effect on GHG - they reduce the level of GHG. For further investigation it will be interesting to extend the research area by including other European countries which are at various stages of development.

\section{REFERENCES}

1. Adom P., Bekoe W., Amuakwa-Mensah F., Mensah J.T., Botchway E. 2012. Carbon dioxide emissions, economic growth, industrial structure, and technical efficiency: Empirical evidence from Ghana, Senegal, and Morocco on the causal dynamics Energy, Volume 47, Issue 1, 314-325. doi.org/10.1016/j.energy.2012.09.025

2. Akbostanci, E.; Turut-Asik, S.; Tunc, G.I. The relationship between income and environment in Turkey: is there an environmental Kuznets curve?, 2009. Energy Policy 37: 861-867.

3. Ansuategi, A.; Escapa, M. Economic growth and greenhouse gas emissions, Ecological Economics, 2002, 40, p. 23-37.

4. Baodong L., Xiaokun W. 2011. Economic Structure and Intensity Influence Air Pollution Model Original Energy Procedia, Volume 5, 803-807 doi.org/10.1016/j.egypro.2011.03.141.

5. Buehn A.; Farzanegan M. Hold your breath: a new index of air pollution. Energy economics. 2013.37 p. 104-113.

6. Cole, M. A.; Rayner, A. J.; Bates, J. M. 1997. The Environmental Kuznets Curve: An Empirical Analysis, Environment and Development Economics 2(4): 401-16.

7. Culas, R. REDD and forest transition: Tunneling through the environmental Kuznets curve, Ecological Economics 2012.79:44-51. School of Agricultural and Wine Sciences, Charles Sturt University, PO Box 883, Orange NSW 2800, Australia. http://dx.doi.org/10.1016/j.ecolecon.2012.04.015

8. Dinda, S. Environmental Kuznets curve hypothesis: a survey, Ecological Economics, 2004, 49, p. 431-455. doi:10.1016/j.ecolecon.2004.02.011

9. Esteve, V.; Tamarit, C. Is there an environmental Kuznets curve for Spain? Fresh evidence from old data, 2012. Economic Modelling 29: 2696-2703.

10. Europe 2020. A strategy for smart, sustainable and inclusive growth. [online], [cited 17 September 2012]. Available from Internet: http://ec.europa.eu/europe2020/index_en.htm

11. Eurostat statistical book. 2010 Using official statistics to calculate greenhouse gas emissions. A statistical guide. [online], [cited 10 November 2012] Available from Internet: http://epp.eurostat.ec.europa.eu/cache/ITY OFFPUB/KS-31-09272/EN/KS-31-09-272-EN.PDF

12. Eurostat. [online], [cited 17 September 2012].Available from internet: $<\mathrm{http}: / /$ epp.eurostat.ec.europa.eu/>

13. Eviews 4 Users guide. 2000. Irvine CA: Quantitative Micro Software, LLC.

14. Fosten, J.; Morley B.; Taylor, T. 2012. Dynamic misspecification in the environmental Kuznets curve: Evidence from $\mathrm{CO} 2$ and $\mathrm{SO} 2$ emissions in the United Kingdom, Ecological Economics 76: 25-33. doi:10.1016/j.ecolecon.2012.01.023

15. Galeotti, M.; Lanza, A.; Pauli, F. Reassessing the environmental Kuznets curve for $\mathrm{CO} 2$ emissions: A robustness exercise, Ecological Economics, 2006, 57(1), p. 152-163. doi:10.1016/j.ecolecon.2005.03.031.

16. Gassebner M, Lamla M.J, Sturm J. Determinants of pollution: what do we really know? Oxf. Econ. Pap., 2011, 63, p. 568 - 595. doi: 10.1093/oep/gpq029

17. Grossman, G. M.; Krueger, A. B. 1991. Environmental impact of a North American free trade agreement. Working Paper 3194. Cambridge, MA: National Bureau of Economic Research. [online], [cited 10 July 2012]. Available from Internet: http://www.nber.org/papers/w3914.pdf.

18. Grossman, G. M.; Krueger, A. B. 1995. Economic growth and the environment, Quarterly Journal of Economics 110:353-377. [online], [cited 15 July 2012]. Available from Internet: https://groups.nceas.ucsb.edu/sustainability-science/weeklysessions/session-2-09.20.2010-sustainability-science-and-sustainabledevelopment/supplemental-readings-from-umngroup/Grossman1995.pdf/view

19. Hamit-Haggar M. Greenhouse gas emissions, energy consumption and economic growth: A panel cointegration analysis from Canadian industrial sector perspective. 2012. Energy Economics 34:358-364.

20. He J.; Wang H. 2012. Economic struvture, development policy and environmental quality: An empirical analysis of environmental Kuznets curves with Chinese municipal data. Ecological Economics, Volume 76:49-59.

21. Holtz-Eakin, D.; Selden, T.M. Stoking the fires? CO2 emissions and economic growth. Journal of public economics, 1995, 57, p. 85-101. 
22. Huang, W. M.; Lee, G. W. M.; Wu C. 2008. GHG emissions, GDP growth and the Kyoto Protocol: A revisit of Environmental Kuznets Curve hypothesis, Energy Policy 36(1): 239-247. doi:10.1016/j.enpol.2007.08.035

23. Kuznets, S. Economic growth and income inequality. The American Economic Review, 1955, 4(1),p. 1-28. [online], [cited 1 May 2012]. Available from Internet: http://web.undp.org/latinamerica/inequality/bibliography/ Economic\%20Growth\%20and\%20Income\%20Inequality.pdf

24. Kyoto protocol. United Nations Framework Convention on Climate Change. 1997. [online], [cited 18 September 2012]. Available from Internet: http://unfccc.int/kyoto_protocol/items/2830.php

25. Lamla M.J., Long-run determinants of pollution: A robustness analysis, Ecological Economics, 2009., vol. 69, Issue 1, 15 November 9, p. 135-144, doi: 10.1016/j.ecolecon.2009.08.002

26. Lapinskienè G.; Tvaronavičienė M.; Vaitkus The emissions of greenhouse gases and economic growth - the evidence of the presence of the Environmental Kuznets curve in the European Union countries, Technological and Economic Development of Economy, 2013. Will be published.

27. Lin, C.Y.; Liscow, Z. D.,. Endogeneity in the Environmental Kuznets Curve: An Instrumental Variables Approach, American J. of Agricultural Economics 2013. 95 (2): 268-274.

28. Saboori, B.; Sulaiman', J.; Mohd, S.. Economic growth and $\mathrm{CO}_{2}$ emissions in Malaysia: A cointegration analysis of the Environmental Kuznets Curve, 2012. Energy Policy 51:184-191.

29. Schmandt, J. 2010. George P. Mitchell and the Idea of Sustainability. Texas A\&M University Press. $192 \mathrm{p}$.

30. Selden, T.M.; Song D. Environmental Quality and Development: Is there a Kuznets Curve for Air Pollution Emissions? Evironmental economics and management, 1994, 27 p. 147-162

31. Stern, D. Rise and fall of the Environmental Kuznets Curve. World Development, 2004, 32(8), p. 1419-1439. doi:10.1016/j.worlddev.2004.03.004

32. Stern, D.; Ma, C. 2008. Biomass and China's carbon emissions: A missing piece of carbon decomposition, Energy Policy 36(7): 2517 2526. doi:10.1016/j.enpol.2008.03.013.

33. World Bank 1992. Development and the Environment. [online], [cited 8 September 2012]. Available from Internet: http://econ.worldbank.org/external/default/main?pagePK=64165259\&t heSitePK=469372\&piPK=64165421\&menuPK $=64166093 \&$ entityID $=0$ $00178830 \quad 9810191106175$

34. World Economic Forum. The Global Competitiveness Report 20112012. [online], [cited 16 September 2012]. Available from Internet: http://www3.weforum.org/docs/WEF_GCR_Report_2011-12.pdf>

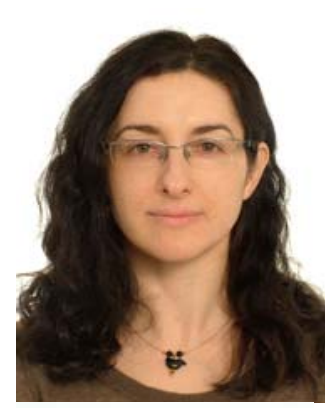

Giedrè Lapinskienè $\mathrm{PhD}$ student at Vilnius Gediminas Technical University (VGTU), Department of Enterprise Economics and Management. Research interests: sustainable business, sustainable development, environmental economics.

Address: Vilnius Gediminas Technical University, Saulètekio ave. 11, LT-10223 Vilnius, Lithuania

E-mail: giedre.lapinskiene@dok.vgtu.lt

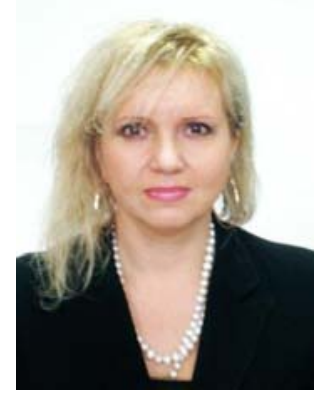

E-mail:manuela@vgtu.lt

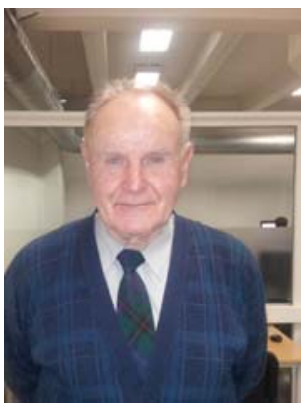

Manuela Tvaronavičienė $\mathrm{PhD}$, works as Associate Professor at Vilnius Gediminas Technical University, Department of Economics and Management of Enterprises. Her research interests involve tax systems reforms in transition economies, investigation of legal tools for conditioning of business environment and factors stimulating investment processes in transition economies.

Address: Vilnius Gediminas Technical University, Saulètekio ave. 11, LT-10223 Vilnius, Lithuania

Pranas Vaitkus is Associate Professor at the department of Mathematical Statistics at Vilnius University (VU). He obtained his $\mathrm{Ph} . \mathrm{D}$. from the Vilnius University, and through his extensive 40 years career in research mainly focused on prediction and classification problems using locally weighted regression, neural networks, extreme learning machines and different ensembles models. Besides that he also made a significant research in feature extraction using Hilbert-Schmidt norms, application of mathematical statistics in economics and medicine. Few years ago a rapidly growing big data company invited P.Vaitkus to be an advisory board member resposnible for leading the company through lates] t data mining aproaches.

Address: Vilnius University, Naugarduko st. 24, LT-03225 Vilnius, Lithuania

E-mail:vaitkuspranas@gmail.com 